\title{
Protective effect of sesame (sesamum indicum) seed oil against hypercholesterolemic in sprague-dawley male rats
}

\author{
Maria ASLAM ${ }^{1 *}$, Muhammad Asim SHABBIR ${ }^{1}$, Imran PASHA ${ }^{1}$, Rizwan SHUKAT ${ }^{1}$, Umera SIDDIQUE ${ }^{1,2}$, \\ Muhammad Faisal MANZOOR ${ }^{3,4 *}$ (D), Sehrish AYUB ${ }^{1}$
}

\begin{abstract}
To explore the protective effect of sesame seed oil (SSO) extracted from Til-06 sesame variety in Sprague-Dawley male rats against the management of hypercholesterolemia, the current two-phase study was conducted. In the first phase, oil was taken out from the sesame seeds (Til-06) and physicochemical analysis was carried out to find out the content of oil following by the evaluation of the quality attributes of extracted oil. In the second phase, efficacy was carried out to check the hyperlipidemic activity of sesame seed oil. Randomly distributed twenty (20) rats into 5 different groups with four (04) rats in each group and for 60 days fed as follow; the first group was fed on a basal diet, while the other groups were fed with 2, 4, 6 and $8 \%$ SSO plus basal diet. Blood samples were collected at the beginning and end of the study for biochemical study i.e. lipid profile which includes high-density lipoprotein (HDL-C), triglycerides (TG), low-density lipoprotein (LDL-C), total cholesterol (TC), and very-low-density lipoprotein (VLDL) and antioxidant status. Findings of the present study indicate that the oral administration of SSO significantly $(P<0.05)$ improved the antioxidant status with lower TC, LDL-C, TG, VLDL-C, and higher HDL-C values of hypercholesterolemic rats.
\end{abstract}

Keywords: antioxidant status; hyperlipidemia; lipid profile; sesame seed oil.

Practical Application: Current findings brightened the possibility of sesame seed oil utilization in diet-based therapies against hyperlipidemia and oxidative stress.

\section{List of abbreviations}

SSO- Sesame seed oil

HDL-C -High-density lipoprotein Cholesterol

TG -Triglycerides

LDL-C- Low-density lipoprotein Cholesterol

TC- Total cholesterol

VLDL-C-Very low-density lipoprotein Cholesterol

AHA-American heart association

CVDs- Cardiovascular Diseases

NCDs- Noncommunicable diseases

AARI-Ayub Agriculture Research Institute

NIH- National Institute of Health

MDA level- Malondialdehyde level

TAC-Total antioxidant capacity

S.D- Standard Deviation

\section{Introduction}

Sesame seeds (Sesamum indicum), named as "queen of oilseeds" is the oldest and important oil yielding crop having many local names like Kunjad and Til in Unani, Sesame, and Gingelly in English, and Snehphala and Tila in Ayurveda (Hassan, 2012). It is cultivated across the tropical, subtropical, and southern temperate areas due to its high therapeutic and nutritional importance. In Asian countries, sesame seed has been used to improve health conditions and prevent various illnesses for many decades. The high level of mono- and polyunsaturated fatty acids, vitamin E, phytosterols, fiber, and other nutraceutical components as phenolic compounds, bioactive lignans, sesamin, episesamin, sesamol, and sesamolin make the sesame, a unique healthy source (Namiki, 2007). By yield Ethiopia, China, Nigeria, India, Myanmar, Burkina Faso, United Republic of Tanzania, Somania, Uganda, and Nigeria are the main ten sesame growing countries of sesame (Nzikou et al., 2009).

By refining the extracted oil from the seeds of sesame, up to $65 \%$ of the world's sesame is processed into oil and meal $35 \%$ for meals (Borchani et al., 2010). After oil extraction, the meal contains $35-50 \%$ protein and is used for livestock and poultry as feed (Hassan, 2012). Environmental factors such 
as soil sort and atmosphere affect the quality and quantity of the oil and plant's growth. The unsaturated fatty acids in the oil determine the quality of the oil. Sesame oil is a plant-based oil and shows an ideal balance between omega- 6 to omega- 3 polyunsaturated fatty acid (Chowdhury et al., 2002). It is rich in oleic acid (53.8\%), linoleic acid (22.1\%), and alpha-Linolenic acid and glycerides of myristic, palmitic, and stearic acids. Sesamine-a crystalline substance and sesamolin are also found in sesame oil due to the presence of these lignins the oxidative stability of sesame oil has been increased (Lee et al., 2008). The presence of secondary metabolites and bioactive compounds such as terpenes, steroids, and phenolic compounds makes oil useful pharmaceutically and for herbal medications. In recent studies using modern methods, the antihypertensive, antioxidative, hypocholesterolemic, anticancer, and immunoregulating properties of sesame oil have been evaluated and these health benefits are attributed to the lignins and glycosides which are present in the oil (Miyahara et al., 2001). The ability of sesame seeds to reduce plasma cholesterol is due to linoleic acid and by a high content of dietary fiber (Mensink et al., 2003).

The American heart association (AHA) defined hyperlipidemia as an abnormal state of fats in the blood. Depending on the type of lipid level having elevated level in the blood, hyperlipidemia is categorized into two types one is hypercholesterolemia- high cholesterol level in the blood and the second is the hypertriglyceridemia-high level of triglycerides in the blood (Jain et al., 2007). The major reasons for mortality around the world are obesity, hypertension, diabetes mellitus, stroke, and cardiovascular ailment (CVDs) and are known as Chronic non-communicable diseases (NCDs) and are emerging as an issue of developed and developing nations and hyperlipidemia is also a major cause for these illnesses (Gadiraju et al., 2015). Sesame oil contains a great proportion of omega- 3 and omega- 6 fatty acids which makes it highly stable from oxidation and makes it therapeutically and nutritionally important. It has hypolipidemic and hypocholesterolemic potential which makes this oil useful for preventing hyperlipidemia and its associated diseases like cardiovascular diseases (Dzisiak, 2004).

To explore the protective effects of sesame seed oil against the management of hypercholesterolemia and oxidative stress in Sprague Dawley male rats by in vitro study the current study was planned.

\section{Materials and methods}

\subsection{Procurement of material and extraction of oil}

Til-06 variety of sesame seeds was obtained from Ayub Agriculture Research Institute (AARI), Faisalabad Pakistan. Other raw materials required for the experimental study were procured from the local market. Reagents and kits were procured from Sigma chemicals (USA) with analytical grade. The procured seeds were washed properly, dried, de-hulled, and mashed into fine powder by using a food grinder to 40 mesh size.

\subsection{Oil extraction}

Sesame seed oil was extracted through the Soxhlet method. For oil extraction, $50 \mathrm{~g}$ sesame seed powder was extracted by petroleum ether at $50{ }^{\circ} \mathrm{C}$ for 8 hours. Sesame seed oil (SSO) was recovered in a rotary evaporator (Model N-1, Eyela, Tokyo Rikakikal Co., Ltd., Japan) by evaporating solvent (Nzikou et al., 2009).

\subsection{Experimental design and study plan}

The hypolipidemic potential of sesame seed oil (SSO) in the management of hyperlipidemia was checked by conducting in vitro study for 60 days on Sprague Dawley male rats distributed randomly in 5 groups comprising of six (04) rats in each group weighing 200-220 g (Table 1). The study was carried out under controlled standard conditions of light, temperature, and humidity by using the ethical guidelines of the International Association, the animals were caged individually. Experimental diets composed of 2, 4, 6, and $8 \% \mathrm{SSO}$ named $\mathrm{T}_{1}, \mathrm{~T}_{2}, \mathrm{~T}_{3}$, and $\mathrm{T}_{4}$ while the rest of the formulation was the same as mentioned by the National Institute of Health (NIH), Islamabad, Pakistan. Daily, water, and diet intake of rats were monitored. By cardiac puncture, blood samples were collected for further biochemical study while following the method of Tsuchihashi et al. (2001) serum was collected to analyze the levels of TC, HDL-C, LDL-C, and TG.

\subsection{Physical measurements}

Feed intake of rats was noticed every week while body weight was monitored at $0,21^{\text {st, }}$ and $42^{\text {nd }}$ day.

\subsection{Biochemical analysis}

Lipid profile

The lipid profile including serum high-density lipoproteins (HDL-C), low-density lipoproteins (LDL-C), total cholesterol (TC), and triglycerides (TG) was examined. The CHOD-PAP method was used for the estimation of serum total cholesterol taking after the convention Kim et al. (2011). The HDL-Cholesterol was determined by the method of enzymatic colorimetric strategy (Randox HDL-C precipitant kit) (Alshatwi et al., 2010). VLDL-Cholesterol was calculated by taking the methodology as depicted by Garg et al. (2014) and LDL-cholesterol fraction obtained by subtracting HDL-cholesterol from total cholesterol (TC). The serum triglyceride was calculated in the serum by liquid triglyceride (GPO-PAP) strategy by Kim et al. (2011).

Table 1. Diet plan.

\begin{tabular}{ccc}
\hline Group & Treatments & Diet Inoculated \\
\hline Group I & T0 & $\begin{array}{c}\text { Control positive (normal rats), fed on a } \\
\text { normal diet }\end{array}$ \\
Group II & T1 & SSO treated normal rats, normal diet + 2\% SSO \\
Group III & T2 & SSO treated normal rats, normal diet + 4\% SSO \\
Group IV & T3 & SSO treated normal rats, normal diet + 6\% SSO \\
Group V & T4 & SSO treated normal rats, normal diet $+8 \%$ SSO \\
\hline
\end{tabular}




\section{Antioxidant status}

Oxidative damage in experimental rats was assessed by the MDA level (Ohkawa et al., 1979) and total antioxidant capacity (TAC) (Hermes-Lima \& Storey, 1995). The antioxidant status of experimental rats was examined by glutathione contents (Beutler et al., 1963).

\subsection{Statistical analysis}

The information obtained from the present study was subjected to statistical investigation for the level of significance as indicated by the standard method as depicted by (Hines et al., 2008) and the results were expressed as mean \pm S.D using analysis of variance to test for differences in the groups.

\section{Results}

\subsection{Effect of SSO on Feed intake and body weight}

The results of the efficacy study as described in Figure 1 showed that a significant decrease in feed intake occurs by increasing the administered amount of sesame oil. Moreover, a significant decrease in body weight of rat has been noticed from the start of the study until the end followed by the increase in the dose of sesame oil as shown in Figure 2. All the four treatments ( $\mathrm{T} 1, \mathrm{~T} 2, \mathrm{~T} 3$, and $\mathrm{T} 4$ ) proved to be effective in lowering the body weight and feed intake of rats when observed on every $21^{\text {st }}$ and $42^{\text {nd }}$ day of the study. T4 was found to be the most effective dose for lowering the bodyweight from $249.54 \mathrm{~g}$ to $221.46 \mathrm{~g}$ in 42 days.

\subsection{Effect of SSO on serum lipid profile}

Diets containing SSO significantly reduced the serum lipid profile with elevation in HDL-C from $28.60 \pm 2.75$ to $41.45 \pm 2.62$ in rats (Table 2). SSO has a significant effect in declining VLDL-C, TG, LDL-C, and TC levels as a dose-dependent tendency in experimental rats. Data in Table 2 indicates that the lipid-lowering effect is proportional to the SSO dose because of the increase in sesame lignin contents.

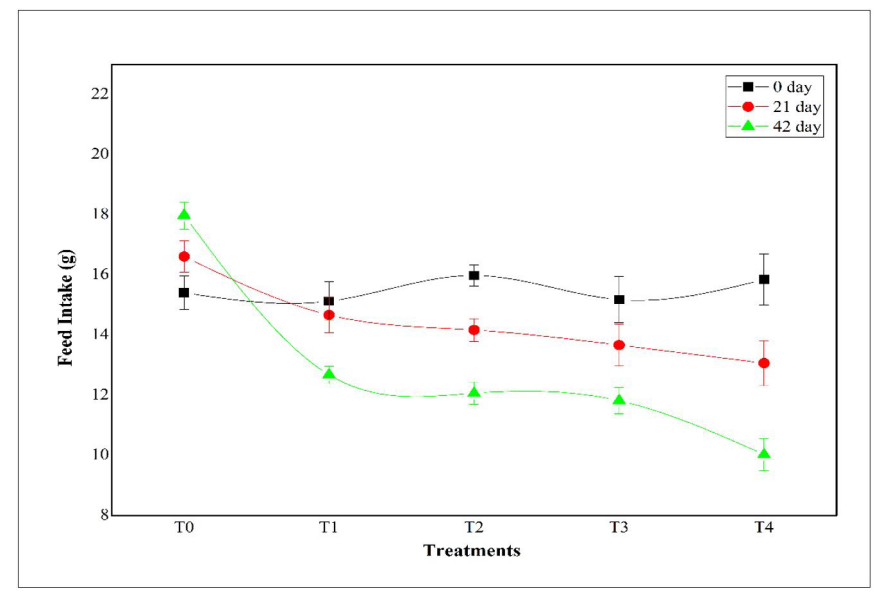

Figure 1. Effect of sesame seed oil on feed intake. T0 = Normal Diet, T1 $=$ Normal Diet $+2 \%$ SSO, T2 $=$ Normal Diet $+4 \%$ SSO, T3 $=$ Normal Diet $+6 \%$ SSO, T4 $=$ Normal Diet $+8 \%$ SSO.

\subsection{Effect of SSO on antioxidant status}

Table 3 showed the effect of SSO on antioxidant status in normal and experimental rats. Data revealed that SSO has a significant effect $(\mathrm{P}<0.05)$ on antioxidant status in experimental rats. The incorporation of SSO significantly improved the total antioxidant capacity of rats as compared to normal rats in a dose-dependent trend. The antioxidant capacity in T0 was $0.79 \pm 0.061 \mathrm{IU} / \mathrm{mL}$ which increases with the increase in the dose of sesame oil to $0.86 \pm 0.023 \mathrm{IU} / \mathrm{mL}$ in $\mathrm{T} 4$.

\section{Discussion}

The current study was in agreement with the previous study in which Cherian (2008) found that the feed comprised of $3 \%$ and $4.5 \%$ SSO (sesame seed oil) lowers the feed intake significantly in contrast to the diet contained $1.5 \%$ sesame oil because of the higher energy level in these diets and the control feed conversion ratio was not affected. The outcome of the research was in line with findings of Nandakumaran et al. (2015) who investigated that the administration of the $1 \mathrm{~mL} /$ day, $2 \mathrm{~mL} /$ day, and $4 \mathrm{ml} /$ day of sesame oil for 30 days caused a substantial decrease in the body weight from 229, 235, and $236 \mathrm{~g}$ at the start of the experiment to 211,212 and $208 \mathrm{~g}$ respectively after the 30 days.

SSO has a significant effect in declining VLDL-C, TG, LDL-C, and TC levels as a dose-dependent tendency in experimental rats. Data indicates that the lipid-lowering effect is proportional to the SSO dose because of the increase in sesame lignin contents. The results are in close collaboration with the previous study by Hoan \& Anh (2016) who investigated that lower circulating concentration of lipids in rabbits supplemented with 5 percent sesame seed oil. Namiki (2007) found that administration of $1 \mathrm{ml}, 2 \mathrm{ml}$, and $4 \mathrm{ml}$ of sesame seed oil per day explicated a lipid-lowering influence. Reena \& Lokesh (2007) found that rats fed with coconut and sesame seed oil showed a $12.9 \%$ reduction in triglycerides in contrast to the rat's given coconut oil. El-Baz et al. (2015) found the 196.3 and 206.15\% lipid reduction in hypercholesterolemic rat models by administrated at prophylactic 5 and 10\% black sesame seed oil. The LDL level decreased with

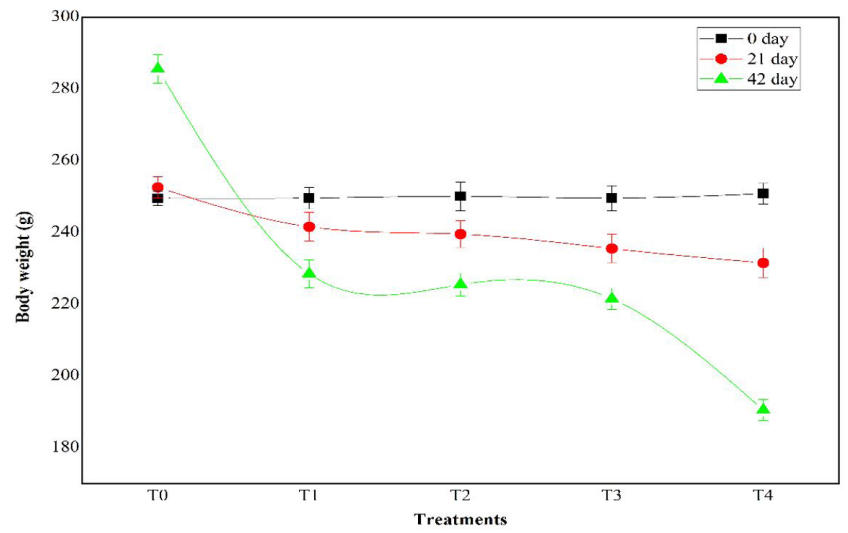

Figure 2. Effect of sesame seed oil on body weight. T0 = Normal Diet, $\mathrm{T} 1=$ Normal Diet $+2 \%$ SSO, T2 $=$ Normal Diet $+4 \%$ SSO, T3 $=$ Normal Diet $+6 \%$ SSO, T4 $=$ Normal Diet $+8 \%$ SSO . 
Lipid-lowering effect of sesame seed oil

Table 2. Comparisons of the serum lipid profiles before and after the dietary sesame intervention.

\begin{tabular}{cccccc}
\hline Treatments & Triglycerides $(\mathrm{mg} / \mathrm{dl})$ & Total Cholesterol $(\mathrm{mg} / \mathrm{dl})$ & LDL-C $(\mathrm{mg} / \mathrm{dl})$ & HDL-C $(\mathrm{mg} / \mathrm{dl})$ & VLDL-C $(\mathrm{mg} / \mathrm{dl})$ \\
\hline T0 & $99.99 \pm 6.74$ & $137.33 \pm 0.66$ & $66.20 \pm 0.66$ & $26.04 \pm 0.61$ & $66.20 \pm 0.50$ \\
T1 & $107.74 \pm 1.03$ & $121.02 \pm 0.93$ & $54.67 \pm 0.93$ & $28.89 \pm 0.62$ & $54.67 \pm 0.61$ \\
T2 & $102.98 \pm 1.04$ & $119.53 \pm 0.89$ & $53.38 \pm 0.92$ & $29.62 \pm 0.63$ & $53.38 \pm 0.62$ \\
T3 & $101.66 \pm 1.03$ & $117.10 \pm 1.02$ & $50.58 \pm 0.90$ & $31.44 \pm 0.60$ & $50.59 \pm 0.59$ \\
T4 & $97.27 \pm 1.02$ & $115.46 \pm 0.99$ & $48.88 \pm 0.91$ & $32.39 \pm 0.60$ & $48.8 \pm 0.64$ \\
\hline
\end{tabular}

$\mathrm{T} 0=$ Normal Diet, $\mathrm{T} 1=$ Normal Diet $+2 \% \mathrm{SSO}, \mathrm{T} 2=$ Normal Diet $+4 \% \mathrm{SSO}, \mathrm{T} 3=$ Normal Diet $+6 \% \mathrm{SSO}, \mathrm{T} 4=\mathrm{Normal}$ Diet $+8 \% \mathrm{SSO}$.

Table 3. Effect of SSO on the antioxidant status of normal and experimental rats.

\begin{tabular}{cc}
\hline Treatments & Total antioxidants capacity $(\mathrm{TAC})(\mathrm{IU} / \mathrm{mL})$ \\
\hline T0 & $0.79 \pm 0.061$ \\
T1 & $0.82 \pm 0.031$ \\
T2 & $0.83 \pm 0.027$ \\
T3 & $0.84 \pm 0.025$ \\
T4 & $0.86 \pm 0.023$ \\
\hline
\end{tabular}

$\mathrm{T} 0=$ Normal Diet, $\mathrm{T} 1=$ Normal Diet $+2 \% \mathrm{SSO}, \mathrm{T} 2=$ Normal Diet $+4 \% \mathrm{SSO}, \mathrm{T} 3=$ Normal Diet $+6 \%$ SSO, T $4=$ Normal Diet $+8 \%$ SSO.

increasing the concentrations of administered sesame oil and the result found were in close collaboration with the previous findings, polyunsaturated and monounsaturated fatty acids could affect the lipoprotein metabolism in hypocholesterolemic models. The LDL-C was decreased in rats fed sesame seed oil was reduced by $38.6 \%$ as compared to the rat's given coconut oil (Rajeshwari et al., 2005).

It was observed that the incorporation of SSO in the diet reduced the formation of free radicals in the lipid peroxidation process by increasing the total antioxidant capacity. Similar results were found by Rezq (2019) as they observed a reduction in oxidative stress in hypercholesterolemic rabbits in the dose-dependent trend of sesame seed powder. Jillian (2010) stated that sesame seed oil contains phytoestrogen and could increase total antioxidant capacity as estrogen lessened the TG and LDL-C and enhancing antioxidant status.

\section{Conclusion}

The decreased feed intake and body weight were observed as the oil contained lignins which gave the feeling of satiety and more calories. The oil has antilipolytic effects in the body and prevents LDL-C from being oxidized. Increased excretion of neutral sterols, bile acid, and cholesterol causes the cholesterol-lowering effects by the administration of different concentrations of sesame oil to hypercholesterolemic rats. The cholesterol-lowering activity of sesame seed oil is related to phytoestrogen which increases the HDL and lowers LDL, VLDL, TC, and TG. A higher concentration of sesame seed oil has a higher content of phytoestrogen and lignin so it has a significantly better impact on the oxidative stress and lipid profile in hypercholesterolemic rats.

\section{References}

Alshatwi, A. A., Al Obaaid, M. A., Al Sedairy, S. A., Al-Assaf, A. H., Zhang, J. J., \& Lei, K. Y. (2010). Tomato powder is more protective than lycopene supplement against lipid peroxidation in rats. Nutrition Research (New York, N.Y.), 30(1), 66-73. PMid:20116662.

Beutler, E., Duron, O., \& Kelly, B. M. (1963). Improved method for the determination of blood glutathione. The Journal of Laboratory and Clinical Medicine, 61, 882-888. PMid:13967893.

Borchani, C., Besbes, S., Blecker, C., \& Attia, H. (2010). Chemical characteristics and oxidative stability of sesame seed, sesame paste, and olive oils. Journal of Agricultural Science and Technology, 12, 585-596.

Cherian, G. (2008). Egg quality and yolk polyunsaturated fatty acid status in relation to broiler breeder hen age and dietary n-3 oils. Poultry Science, 87(6), 1131-1137. PMid:18493002.

Chowdhury, S. R., Chowdhury, S. D., \& Smith, T. K. (2002). Effects of dietary garlic on cholesterol metabolism in laying hens. Poultry Science, 81(12), 1856-1862. PMid:12512577.

Dzisiak, D. (2004). New oils reduce saturated and trans fats in processed foods. Cereal Foods World, 49(6), 331.

El-Baz, F. K., Salama,, Z., Aly, H. H., \& Taie, H. (2015). Potency of sesame oil as antihypercholesterolemic agent in rats fed high-fat diet. International Journal of Pharma and Bio Sciences, 6(3), B177-B189.

Gadiraju, T. V., Patel, Y., Gaziano, J. M., \& Djoussé, L. (2015). Fried food consumption and cardiovascular health: a review of current evidence. Nutrients, 7(10), 8424-8430. PMid:26457715.

Garg, N., Agrawal, Y. B., \& Gupta, S. (2014). A study of lipid profile levels in diabetics and non-diabetics taking TC/HDL ratio and LDL/ HDL ratio into consideration. Journal, Indian Academy of Clinical Medicine, 15(3), 192-195.

Hassan, M. A. (2012). Studies on Egyptian sesame seeds (Sesamum indicum L.) and its products 1-physicochemical analysis and phenolic acids of roasted Egyptian sesame seeds (Sesamum indicum L.). World Journal of Dairy Food Sciences, 7(2), 195-201. http://dx.doi. org/10.5829/idosi.wjdfs.2012.7.2.1112.

Hermes-Lima, M., \& Storey, K. B. (1995). Xanthine oxidase and xanthine dehydrogenase from an estivating land snail. Zeitschrift fur Naturforschung. C, Journal of biosciences, 50(9-10), 685-694. PMid:8579686.

Hines, W. W., Montgomery, D. C., Goldsman, D. M., \& Borror, C. M. (2008). Probability and statistics in engineering. Boca Raton: John Wiley \& Sons.

Hoan, N. D., \& Anh, K. M. (2016). The effect of different levels of sesame oil on productive performance, egg yolk and blood serum lipid profile in laying hens. Open Journal of Animal Sciences, 6(1), 85-93.

Jain, K. S., Kathiravan, M. K., Somani, R. S., \& Shishoo, C. J. (2007). The biology and chemistry of hyperlipidemia. Bioorganic \& Medicinal Chemistry, 15(14), 4674-4699. http://dx.doi.org/10.1016/j. bmc.2007.04.031. PMid:17521912. 
Jillian, S. (2010). Hormonal enzyme systems and botanical agents. Medicines from the Earth, 4(7), 134-137.

Kim, J. Y., Paik, J. K., Kim, O. Y., Park, H. W., Lee, J. H., Jang, Y., \& Lee, J. H. (2011). Effects of lycopene supplementation on oxidative stress and markers of endothelial function in healthy men. Atherosclerosis, 215(1), 189-195. http://dx.doi.org/10.1016/j.atherosclerosis.2010.11.036. PMid:21194693.

Lee, J., Lee, Y., \& Choe, E. (2008). Effects of sesamol, sesamin, and sesamolin extracted from roasted sesame oil on the thermal oxidation of methyl linoleate. LWT - Food Science and Technology, 41(10), 1871-1875. https://doi.org/10.1016/j.lwt.2007.11.019.

Mensink, R. P., Zock, P. L., Kester, A. D., \& Katan, M. B. (2003). Effects of dietary fatty acids and carbohydrates on the ratio of serum total to HDL cholesterol and on serum lipids and apolipoproteins: a metaanalysis of 60 controlled trials. The American Journal of Clinical Nutrition, 77(5), 1146-1155. PMid:12716665.

Miyahara, Y., Hibasami, H., Katsuzaki, H., Imai, K., Osawa, T., Ina, K., \& Komiya, T. (2001). Sesaminol from sesame seed induces apoptosis in human lymphoid leukemia Molt 4B cells. International Journal of Molecular Medicine, 7(5), 485-488. PMid:11295108.

Namiki, M. (2007). Nutraceutical functions of sesame: a review. Critical Reviews in Food Science and Nutrition, 47(7), 651-673. PMid:17943496.

Nandakumaran, M., Al-Sannan, B., George, S., Nair, A. R., \& Mohammed, A. (2015). Sesame oil administration does not alter hematologic and metabolic parameters in female rats. Journal of Bio Innovation, 4(3), 108-118.
Nzikou, J., Matos, L., Bouanga-Kalou, G., Ndangui, C. B., PambouTobi, N. P. G., Kimbonguila, A., Silou, Th., Linder, M., \& Desobry, S. (2009). Chemical composition on the seeds and oil of sesame (Sesamum indicum L.) grown in Congo-Brazzaville. Advance Journal of Food Science and Technology, 1(1), 334-340.

Ohkawa, H., Ohishi, N., \& Yagi, K. (1979). Assay for lipid peroxides in animal tissues by thiobarbituric acid reaction. Analytical Biochemistry, 95(2), 351-358. PMid:36810.

Rajeshwari, R., Nicklas, T. A., Pownall, H., \& Beresnson, G. S. (2005). Cardiovascular diseases-a major health risk in Asian Indians. Nutrition Research, 25(6), 515-533. https://doi.org/10.1016/j. nutres.2005.04.003.

Reena, M. B., \& Lokesh, B. R. (2007). Hypolipidemic effect of oils with balanced amounts of fatty acids obtained by blending and interesterification of coconut oil with rice bran oil or sesame oil. Journal of Agricultural and Food Chemistry, 55(25), 10461-10469. PMid:17994696.

Rezq, A. A. (2019). Potential protective and ameliorate effects of sesame oil and jojoba oil against potassium bromate (Kbro3)-induced oxidative stress in rats. Journal of Studies and Searches of Specific Education, 3(1, Part 1), 155-189.

Tsuchihashi, K., Ueshima, K., Uchida, T., Oh-mura, N., Kimura, K., Owa, M., Yoshiyama, M., Miyazaki, S., Haze, K., Ogawa, H., Honda, T., Hase, M., Kai, R., \& Morii, I., \& Angina Pectoris-Myocardial Infarction Investigations in Japan. (2001). Transient left ventricular apical ballooning without coronary artery stenosis: a novel heart syndrome mimicking acute myocardial infarction. Journal of the American College of Cardiology, 38(1), 11-18. PMid:11451258. 